\title{
Snoring and excessive daytime somnolence among Polish middle-aged adults
}

\author{
J. Zieliński*, A. Zgierska*, M. Polakowska ${ }^{+}$, L. Finn", P. Kurjata ${ }^{+}$, W. Kupść ${ }^{+}$, T. Young
}

Snoring and excessive daytime somnolence among Polish middle-aged adults. J, Zieliński, A. Zgierska, M. Polakowska, L. Finn, P, Kurjata, W. Kupść, T. Young. C)ERS Journals Ltd 1999.

ABSTRACT: There is considerable interest in the association of snoring and health consequences that have been linked to more severe sleep-disordered breathing, including obstructive sleep apnoea syndrome. The goal of this investigation was to assess the independent association of heavy, habitual snoring and daytime sleepiness.

For this, a cross-sectional, population based study of snoring, sleepiness and other factors was conducted using the Warsaw sample of the Multinational Monitoring of Trends and Determinants of Cardiovascular Diseases (MONICA) study, a populationbased multicentre study of cardiovascular disease. The well-defined MONICA sample of middle-aged males and females also allowed estimation of age- and sex-specific prevalences of habitual snoring in Polish adults. Data on self-reported snoring frequency and loudness, and daytime sleepiness using the Epworth Sleepiness Scale (ESS) and other questions, were collected with a postal questionnaire.

Seventy-nine per cent of the MONICA sample completed the questionnaire, yielding a total of 1,186 participants. Of the total sample, $27 \%$ of the females and $48 \%$ of the males reported habitual snoring ("often" or "always"). There was an independent association of habitual snoring and excessive daytime sleepiness (EDS), sleepiness that interfered with work and with increasing ESS scores. Habitual snorers were 5.8 and 3.1 times more likely to report EDS in active and passive situations, respectively, compared to nonsnorers (all $\mathbf{p}<\mathbf{0 . 0 1}$ ).

It is concluded that habitual snorers, most of whom are probably unlikely to have frank sleep apnoea syndrome, are at substantial risk for daytime sleepiness. These findings add support to the hypothesis that simple snoring is not benign and underscores the need for further research on health outcomes associated with this prevalent condition.

Eur Respir J 1999; 14: 946-950.

Snoring, a widespread complaint among adults, is a hallmark symptom of obstructive sleep apnoea syndrome (OSAS) [1]. Although most people with OSAS are heavy, habitual snorers, most snorers do not have the full-blown syndrome. In the Wisconsin Sleep Cohort Study [2], a population based study of the natural history of sleep disordered breathing (SDB), $81 \%$ of females and $66 \%$ of males who reported habitual snoring showed $<5$ apnoeas and hypopnoeas per hour of sleep (apnoea-hypopnoea index, AHI) as measured by polysomnography. Thus, most self-reported snorers probably lie at the milder end of the severity spectrum of SDB.

Several studies have attempted to determine whether snoring, representing predominantly mild SDB, is also linked with the cardiovascular and behavioural morbidity that has been clinically associated with more severe SDB, i.e., OSAS. Some studies have reported associations between snoring and cardiovascular disorders [3-5]. Of the relatively few population-based epidemiological studies designed primarily to investigate snoring and excessive daytime sleepiness (EDS), all have demonstrated positive associations [6-8] and there is some evidence that upper airway resistance, a predominant feature of snoring, is linked to sleep fragmentation and daytime sleepiness [9$10]$.
*Dept of Respiratory Medicine, Institute of TB and Lung Disease, Warsaw, Poland. Dept of Epidemiology and Prevention of Cardiovascular Disease, Institute of Cardiology, Warsaw, Poland. "Dept of Preventive Medicine, University of Wisconsin, Madison, WI, USA.

Correspondence: J. Zielinski, Dept of Respiratory Medicine, Institute of TB and Lung Diseases, ul. Plocka 26, 01-138 Warszawa, Poland, Fax: 48226912454

Keywords: Excessive daytime somnolence, population study, questionnaire, snoring

Received: June 41998

Accepted after revision May 61999

This work was performed under the terms of the US - Poland Cooperation in Cardiopulmonary Disease conducted through the National Institute of Cardiology (Warsaw, Poland) and the National Heart, Lung and Blood Institute (Bethesda, MD, USA) The study was supported by the Polish State Research Committee grant No. 4 P05D 02011.
The goal of the present study was to test the hypothesis that habitual snoring in the general population is associated with increased daytime sleepiness. The Warsaw sample of the population-based Multinational Monitoring of Trends and Determinants of Cardiovascular Diseases (MONICA) multicentre study [11] provided the opportunity to conduct a survey to investigate self-reported snoring and sleepiness as measured by the Epworth Sleepiness Scale (ESS) [12] and other widely-used questions. In addition, the random stratified sampling procedure used to construct the MONICA sample permitted the estimation of snoring prevalence in Polish middle-aged adults.

\section{Materials and methods}

\section{Sample}

The sample comprised Polish participants in the international MONICA II study, a 10-yr World Health Organization (WHO) project [13]. The target population for the Polish component of the MONICA study was permanent residents, aged 38-67 yrs, of two Warsaw districts: Praga North and Praga South. A random sample from this population, stratified by $10-\mathrm{yr}$ age groups and sex, was selected in 1993 from electoral registers (voting lists for 1991 parliament election) covering both districts. 
Of 2,090 males and females sampled, 1,539 persons were successfully recruited (74\% response). Participation involved completing a mailed questionnaire and an in-hospital examination. For the present study, an additional questionnaire on snoring, sleep problems, daytime sleepiness, demographics and lifestyle was mailed to these participants. A second request was sent to those that did not respond to the initial request. Completed questionnaires were returned by 1,186 , representing a $79 \%$ response rate.

\section{Data collection}

Snoring status was ascertained by the following question: "According to what others have told you, please estimate how often you snore", with response categories of never snored, rarely, sometimes, often and always. Participants who responded "rarely or never" snored were grouped as nonsnorers; those reporting "sometimes" formed the moderate snorers group, and those who answered "often or always" were grouped as habitual snorers.

Several questions were asked to assess daytime sleepiness. The response categories were never, rarely, sometimes, often and do not know. Perceived sleepiness was probed by two questions: "How often do you feel sleepy and want to fall asleep in the daytime?" (Feel Sleepy) and "How often do you wake up unrefreshed regardless of sleep duration?" (Unrefresbed). Sleepiness with a function of impact was assessed by the following questions: "How often do you have uncontrollable sleepiness that interferes with daily activities like reading, watching TV, sitting in a bus, car or train?" (EDS while passive; "How often do you have uncontrollable sleepiness that interferes with daily activities like attending meetings, having a meal, driving a car or activities at work?" (EDS while active), and "How often do you have problems at work as a consequence of sleepiness?" (EDS affects work).

\section{Other variables}

Body mass index (BMI) was calculated as weight in kilograms divided by height in square metres $\left(\mathrm{kg} \cdot \mathrm{M}^{2}\right)$. Smoking was estimated by the number of cigarettes per day; only current smokers were included as smokers. Former smokers were included in the nonsmoking group. Sleepy behaviour was measured with ESS [12], a widely used instrument for self-rating the chance of dozing, on a scale of $0-3$, in eight situations. The ESS was translated into Polish and back-translated to insure the integrity of the questions.

\section{Statistical methods}

Data were analysed with SAS statistical software (Stat Soft, Pulsa, USA) for descriptive statistics, contingency tables, multiple linear and logistic regression, and ordinal logistic regression. Participant responses of "do not know" were considered as missing data.

Respondents and nonrespondents were compared by ttests for continuous variables and Chi-squared tests for categorical data. To evaluate the statistical significance of unadjusted differences between nonsnorers, moderate and habitual snorers, Chi-squared analysis was used for categorical data and linear regression F-tests were used for continuous data.
Risk factors for snoring, including age, BMI, sex and smoking, were modelled using ordinal logistic regression with snoring severity as the outcome (no snoring, moderate snoring and habitual snoring). Smoking was coded zero for past and never smokers and with the number of cigarettes smoked per day for current smokers.

The independent relationship between snoring and ESS was tested using multiple linear regression with the ESS score as a continuous outcome. The relationships between snoring and the other measures of daytime hypersomnolence were estimated using multiple logistic regression with each of the questions coded as a binary outcome. EDS, unrefreshed sleep and EDS in passive situations were divided into "often" versus "never", "rarely" or "sometimes". EDS in active situations and EDS causing work problems were separated into "often" or "sometimes" versus "never" or "rarely". These cut-points were related to the frequency of the "often" response. For EDS in active situations and EDS causing work problems there were not enough "often" responses to separate into one category. For all of these models, snoring was included as a three level categorical variable with nonsnorers as the reference, and the relationships were adjusted for age, BMI and sex.

Statistical significance of linear and logistic regression coefficients was assessed by t-test and Wald Chi-squared tests, respectively. Two-tailed p-values $<0.05$ were considered to indicate statistical significance.

\section{Results}

Questionnaires were returned by 1,186 persons (578 males and 608 females), for a response rate of $79 \%$. Data collected previously by the Warsaw components of the MONICA study on the entire group of 1,503 invitees were used to assess participation bias. A comparison (table 1) of respondents versus nonrespondents revealed no statistically significant differences on sex, age and BMI; the only slight differences noted were less hypertension and less cigarette smoking among respondents. BMI and the proportion of males were lower among respondents, adding some reassurance that there was not a strong participation bias in favour of snorers.

The distribution of self-reported snoring (none or rarely, moderate, habitual) by age and sex categories is given in table 2 . Of the total sample, $27 \%$ of the females and $48 \%$ of the males were habitual snorers.

The characteristics of the sample by snoring status are presented in table 3 . Habitual snorers were predominantly

Table 1. - A comparison of respondents with non-respondents

\begin{tabular}{lcc}
\hline Variable & $\begin{array}{c}\text { Respondents } \\
\mathrm{n}=1186\end{array}$ & $\begin{array}{c}\text { Nonrespondents } \\
\mathrm{n}=317\end{array}$ \\
\hline Age yrs & $49.0 \pm 0.2$ & $48.2 \pm 0.5$ \\
Male \% & 48.7 & 51.7 \\
BMI kg.m ${ }^{2}$ & $27.3 \pm 0.1$ & $27.6 \pm 0.3$ \\
Hypertension \%* & 38.9 & 46.1 \\
systolic BP mmHg* & $130.2 \pm 0.6$ & $133.3 \pm 1.3$ \\
diastolic BP mmHg* & $83.0 \pm 0.4$ & $85.1 \pm 0.8$ \\
Smoking Yes \%* & 39.3 & 47.6 \\
\hline
\end{tabular}

Data are presented as mean $\pm \mathrm{SE}$ or as percentages if indicated. *: chi-squared test $\mathrm{p}<0.05$. BMI: body mass index; BP: blood pressure (mean of two measured blood pressures). 
Table 2. - Age- and sex-specific prevalence of snoring

\begin{tabular}{|c|c|c|c|c|c|c|}
\hline \multirow{2}{*}{ Age yrs } & \multicolumn{3}{|c|}{ Women } & \multicolumn{3}{|c|}{ Men } \\
\hline & Nonsmokers & $\begin{array}{l}\text { Moderate } \\
\text { snorers }\end{array}$ & $\begin{array}{l}\text { Habitual } \\
\text { snorers }\end{array}$ & Nonsmokers & $\begin{array}{l}\text { Moderate } \\
\text { snorers }\end{array}$ & $\begin{array}{l}\text { Habitual } \\
\text { snorers }\end{array}$ \\
\hline $38-39$ & $44(47.8)$ & $34(37.0)$ & $14(15.2)$ & $32(33.3)$ & $31(32.3)$ & $33(34.4)$ \\
\hline $40-49$ & 89 (41.6) & $68(31.8)$ & 57 (26.6) & $39(20.5)$ & $55(29.0)$ & $96(50.5)$ \\
\hline $50-59$ & $80(39.8)$ & $56(27.9)$ & $65(32.2)$ & 36 (18.6) & $56(28.9)$ & $102(52.6)$ \\
\hline $60-67$ & $24(35.8)$ & $26(38.8)$ & $17(25.4)$ & $22(26.2)$ & $25(29.8)$ & 37 (44.1) \\
\hline Total & $237(41)$ & $184(32)$ & $153(27)$ & $129(23)$ & $167(30)$ & $268(48)$ \\
\hline
\end{tabular}

Data are presented as absolute number with percentage in parentheses.

males $(63.7 \%)$, older, more obese and smoked more than moderate snorers or nonsnorers. The occurrence of daytime sleepiness was more pronounced as the snoring frequency increased. Adjusted odds ratios for snoring and potential risk factors are given in table 4. Compared to females, males were 4.7 times as likely to be habitual snorers. Associations with snoring were weaker, but still statistically significant for age and BMI, Current cigarette smoking was a significant risk factor for being a moderate or habitual snorer and the odds ratio increased with the degree of cigarette smoking.

Investigation of the ESS score, after adjustment for the influence of sex, age and BMI, showed that the mean scores differed significantly $(\mathrm{p}<0.05)$ across the snoring categories and increased consistently with the severity of snoring. The mean \pm SEM ESS score of nonsnorers was 7.5 \pm 0.3 , and of moderate and habitual snorers was $7.9 \pm 0.3$ and $9.7 \pm 0.2$, respectively.

Habitual snoring was strongly associated with perceived sleepiness, sleepy behaviour, and sleepiness that affects

Table 3. - Characteristics of sample by snoring status ${ }^{+}$ $(\mathrm{n}=1,138)$

\begin{tabular}{|c|c|c|c|c|}
\hline Variable & $\begin{array}{l}\text { Non- } \\
\text { snorers }\end{array}$ & $\begin{array}{c}\text { Moderate } \\
\text { snorers }\end{array}$ & $\begin{array}{l}\text { Habitual } \\
\text { snorers }\end{array}$ & $\begin{array}{l}\text { Total } \\
\text { sample }\end{array}$ \\
\hline Male $\% * *$ & 35.3 & 47.6 & 63.7 & 49.6 \\
\hline Age yrs ${ }^{\#}$ & $51.0 \pm 0.4$ & $51.9 \pm 0.4$ & $52.7 \pm 0.4$ & $51.9 \pm 0.2$ \\
\hline BMI $\mathrm{kg} \cdot \mathrm{m}^{2 \#}$ & $25.9 \pm 0.2$ & $26.9 \pm 0.2$ & $27.7 \pm 0.2$ & $26.9 \pm 0.1$ \\
\hline Smoking Yes \% & 33.5 & 35.6 & 42.6 & 37.5 \\
\hline Often, ESS ${ }^{\#}$ & $7.3 \pm 0.3$ & $8.0 \pm 0.3$ & $9.9 \pm 0.2$ & $8.5 \pm 0.1$ \\
\hline Often, EDS $\% *$ & 20.4 & 22.9 & 33.7 & 26.1 \\
\hline $\begin{array}{l}\text { Often, unrefreshed } \\
\text { regardless of sleep } \\
\text { duration \%* }\end{array}$ & 14.6 & 18.6 & 25.9 & 20.0 \\
\hline $\begin{array}{l}\text { Often, EDS in } \\
\text { passive } \\
\text { situation } \% * *\end{array}$ & 13.4 & 15.9 & 35.3 & 22.3 \\
\hline $\begin{array}{l}\text { Often, EDS in } \\
\text { active } \\
\text { situations } \% *\end{array}$ & 0.0 & 0.3 & 1.7 & 0.7 \\
\hline $\begin{array}{l}\text { Often, while } \\
\text { driving } \%\end{array}$ & 0.4 & 0.4 & 1.5 & 0.8 \\
\hline $\begin{array}{l}\text { Often, EDS causes } \\
\text { work problems } \\
\% * \hbar\end{array}$ & 2.1 & 2.4 & 2.9 & 2.5 \\
\hline
\end{tabular}

Data are presented as mean \pm SE unless otherwise indicated. ${ }^{+}$: Question: "How often do you snore?", snorers groups: nonsnorers, (answers "never" or "rarely"); moderate snorers (answer, "sometimes"); habitual snorers (answers, "often", or "always"); *: Chi-Square $\mathrm{p}<0.05$; : Mantel-Haenszel Chi-Square $\mathrm{p}<0.05$; ${ }^{\#}$ : overall F-test. BMI: body mass index; ESS: Epworth Sleepiness Scale; EDS: excessive daytime sleepiness. daytime activities. Odds ratios adjusted for age, sex, and BMI (table 5) indicated that habitual snorers, compared to nonsnorers, were 5.8 and 3.1 times more likely to experience EDS in active and passive situations, respectively. Habitual snorers were significantly more likely to feel sleepy odds ratio $(\mathrm{OR})=2.1,95 \%$ confidence intervals $(95 \% \mathrm{CI}) 1.5-2.9)$ and to have work problems attributed to sleepiness $(\mathrm{OR}=1.9,95 \% \mathrm{CI} 1.2-3.1)$. Neither age nor BMI were independently related to daytime sleepiness. Females, compared to males, were more likely to report having work problems as a result of sleepiness.

\section{Discussion}

\section{Prevalence of snoring}

The sex- and age-specific prevalences of snoring in the sample were applied to the age distribution of the middleaged adult Polish population, as reported in 1995 census data [14]. From this extrapolation, it was estimated that among Polish adults in the age range of 35-69 yrs, 25\% of females and $46 \%$ of males were habitual snorers. It is not likely that response bias caused an overestimation of prevalence, but a healthy volunteer bias, as is commonly seen in general population surveys, may have led to a slight underestimation of the snoring prevalence. International comparisons of snoring prevalence based on selfreporting are difficult to interpret due to differences in age and other sample characteristics, question wording, response categories and definitions. A strength of this study was the use of snoring questions and definitions identical to those of the Wisconsin Sleep Cohort Study [2]. The estimated prevalences of habitual snoring in Wisconsin females $(28 \%)$ and males (44\%) are strikingly similar to the Polish estimates of $25 \%$ in females and $46 \%$ in males.

Table 4. - Multiple logistic regression model to predict snoring

\begin{tabular}{lcc}
\hline \multirow{2}{*}{ Variables in model } & \multicolumn{2}{c}{ Odds ratios $(95 \%$ confidence intervals) } \\
\cline { 2 - 3 } & Moderate snorers* & Habitual snorers* \\
\hline Male versus female & $2.2(1.7-2.7)$ & $4.7(3.0-7.4)$ \\
Age 10 yrs increment & $1.2(1.1-1.4)$ & $1.5(1.2-2.0)$ \\
BMI $5 \mathrm{~kg} \cdot \mathrm{m}^{2}$ & $1.5(1.3-1.7)$ & $2.3(1.7-3.0)$ \\
increment & & \\
Smoking & & \\
10 cigarettes versus 0 & $1.3(1.2-1.5)$ & $1.8(1.4-2.2)$ \\
20 cigarettes versus 0 & $1.8(1.4-2.2)$ & $3.1(1.9-5.0)$ \\
30 cigarettes versus 0 & $2.3(1.6-3.3)$ & $5.4(2.7-11.1)$ \\
\hline *: reference is, snoring "never" or "rarely". BMI: body mass \\
index.
\end{tabular}


Table 5. - Multiple logistic regression models to estimate odds ratios (OR) and $95 \%$ confidence intervals $(95 \% \mathrm{Cl})$ for prediction of sleepiness

\begin{tabular}{|c|c|c|c|c|}
\hline $\begin{array}{l}\text { Independent } \\
\text { variables }\end{array}$ & EDS & $\begin{array}{l}\text { Unre- } \\
\text { freshed }\end{array}$ & $\begin{array}{l}\text { EDS in } \\
\text { passive } \\
\text { situations }\end{array}$ & $\begin{array}{l}\text { EDS in } \\
\text { active } \\
\text { situations }\end{array}$ \\
\hline $\begin{array}{l}\text { Male versus } \\
\text { female }\end{array}$ & $\begin{array}{c}1.1 \\
(0.8-1.5)\end{array}$ & $\begin{array}{c}0.4 \\
(0.3-0.6)\end{array}$ & $\begin{array}{c}1.2 \\
(0.9-1.6)\end{array}$ & $\begin{array}{c}0.7 \\
(0.4-1.5)\end{array}$ \\
\hline Age $10 \mathrm{yrs}$ & $\begin{array}{c}0.9 \\
(0.8-1.1)\end{array}$ & $\begin{array}{c}0.9 \\
(0.7-1.1)\end{array}$ & $\begin{array}{c}1.1 \\
(0.9-1.3)\end{array}$ & $\begin{array}{c}1.0 \\
(0.6-1.4)\end{array}$ \\
\hline $\begin{array}{l}\mathrm{BMI} \\
5 \mathrm{~kg} \cdot \mathrm{m}^{2}\end{array}$ & $\begin{array}{c}0.9 \\
(0.7-1.4)\end{array}$ & $\begin{array}{c}0.8 \\
(0.6-1.0)\end{array}$ & $\begin{array}{c}1.2 \\
(1.0-1.4)\end{array}$ & $\begin{array}{c}1.3 \\
(1.0-1.8)\end{array}$ \\
\hline $\begin{array}{l}\text { Snoring* } \\
\text { moderate }\end{array}$ & $\begin{array}{c}1.2 \\
(0.8-1.7)\end{array}$ & $\begin{array}{c}1.7 \\
(1.1-2.5)\end{array}$ & $\begin{array}{c}1.2 \\
(0.8-1.8)\end{array}$ & $\begin{array}{c}1.2 \\
(0.3-4.6)\end{array}$ \\
\hline habitual & $\begin{array}{c}2.1 \\
(1.5-2.9)\end{array}$ & $\begin{array}{c}3.0 \\
(2.0-4.5)\end{array}$ & $\begin{array}{c}3.1 \\
(2.1-4.6)\end{array}$ & $\begin{array}{c}5.8 \\
(1.9-17.1)\end{array}$ \\
\hline
\end{tabular}

*: reference is, snoring "never" or "rarely". EDS: excessive daytime sleepiness, "often" versus "never", "rarely" or "sometimes"; Unrefreshed: feeling unrefreshed regardless of sleep duration, "often" versus "never", "rarely" or "sometimes"; EDS in passive situations: excessive daytime sleepiness in passive situation, "often" versus "never", "rarely" or "sometimes"; EDS in active situations: excessive daytime sleepiness in active situations, "often" or "sometimes" versus "never" or "rarely"; BMI: body mass index.

\section{Snoring risk factors}

Age, obesity and smoking were significantly associated with habitual snoring in this sample of middle-aged Polish adults. Consistent with other studies [15-18], sex was a strong risk factor for snoring: males were 4.7 times as likely as females to snore habitually. The association between snoring and age range of 38-67 yrs was moderate: the adjusted (a)OR for habitual snoring versus nonsnoring was 1.5 for a 10 -yr age increment. Such findings are consistent with many [2, 15-19], but not all [20-23] studies.

Cigarette smoking was also a strong predictor of severe snoring. Only the influence of current cigarette smoking on snoring was analysed in this study. Current smokers were more likely to snore than nonsmokers and there was a dose-response relationship. Heavy smokers had the greatest risk of habitual snoring (versus nonsmokers, $\mathrm{OR}=5.4$, 95\% CI 2.7-11.1). Other studies have reported an association of smoking and snoring, [15-20, 22, 24-26], adding support for a causal role of smoking in snoring. A causal hypothesis would be of considerable public health importance in Poland, where the prevalence of smoking is high: $39.1 \%$ of Poles $(49.9 \%$ of males and $28.4 \%$ of females) aged $>30$ yrs were smokers in 1995 [27].

Smoking may contribute to increasing snoring severity by upper airways narrowing. Smoking results in chronic inflammatory reaction, hyperaemia and oedema of the pharyngeal mucosa [28], reducing pharyngeal lumen. Irritant compounds of cigarette smoke also induce inflammatory changes in the bronchi, hypertrophy of mucus glands and increased mucus production [29] interfering with airflow through the airway. Increased inspiratory effort could then result in increased snoring [15]. This hypothesized causal mechanism is supported by findings that former smokers have a lower risk of snoring compared to current smokers [24].

\section{Snoring and daytime sleepiness}

It was found that habitual snoring was significantly related, independent of age, sex, and BMI, to increased perceived daytime sleepiness, reported sleepy behaviour in both active and passive situations, and to impaired work performance attributed to sleepiness. The findings, accounting for age, sex, and obesity, on a wide range of sleepiness measures, add considerably to previous support of the hypothesis that snoring is an independent risk factor for daytime sleepiness. Positive findings have been reported in nearly all published reports of snoring and sleepiness, but, with the exception of one study [6], have been limited lack of control for important confounding factors or the use of a single sleepiness question as the outcome measures. In the methodologically strongest study, Stradling et al. [6] interviewed 850 British males and measured their nocturnal breathing by oximetry, and found positive ORs for habitual snoring and seven measures of sleepiness (daytime sleepiness and falling asleep in different situations), four of which were statistically significant after controlling for oxygen desaturation dip rate, age, sex, and BMI. Interestingly, snoring was a better predictor of sleepiness than was the nocturnal oxygen desaturation dip rate. Positive associations, independent of age and sex, were found in two Scandinavian studies, each of which used only a single sleepiness variable [7, 8]. Hublin et al. [8] reported ORs $(95 \% \mathrm{CI})$ for habitual snoring and daily daytime sleepiness of $1.3(0.6-2.5)$ for females and 8.6 (5.9-12.0) for males. JENNUM et al. [7] reported an association of habitual snoring with falling asleep during the daytime $(\mathrm{p}=0.0001)$. Two studies with only univariate analyses have also reported positive associations of snoring and sleepiness $[16,20]$. In the single negative study, OLSON et al. [30] did not find any association between EDS and snoring or even SDB. These authors assumed that such a lack of correlation may be caused by the high prevalence of EDS in the whole sample: EDS prevalence was $41 \%$ for those with SDB, and $37 \%$ for snorers and nonsnorers without SDB.

A clear association was not found between moderate snoring and sleepiness after adjustment for BMI, age and sex. A graded association was seen for snoring severity categories with mean ESS score and unrefreshing sleep, but moderate snoring was not significantly related to other measures of sleepiness. It is possible that people who truly have habitual snoring are more aware of their snoring and there is less validity in a self-report of moderate snoring. More misclassification in the moderate snoring category would diminish the real association and make it quite difficult to detect a small OR.

Polysomnography data were not available in this study, so the investigators were not able to exclude people with OSAS and determine the proportion of the association due solely to simple snoring. However, as seen in population studies in which breathing during sleep was monitored, most snorers do not have OSAS [2, 30-32], and thus it is expected that somnolence in simple snorers is responsible for a substantial portion of the association.

In summary, it is concluded that habitual snoring in the adult Polish population, even after adjustment for age, sex and body mass index, was strongly associated with daytime sleepiness. This finding adds support to the hypothesis that simple snoring is not benign and adds 
hypersomnolence to cardiovascular conditions as a potential consequence of snoring. In view of the high prevalence of snoring, these associations raise the question of the clinical significance of snoring. The data indicate that $34 \%$ of habitual snorers have excessive daytime sleepiness often or always, yielding overall estimates of the prevalence of pathologically sleepy habitual snorers to be $9 \%$ in females and $16 \%$ in males. However, before the clinical or public health significance of these estimates can be addressed, prospective studies that quantify the causal role of snoring in hypersomnolence and other health outcomes are needed.

\section{References}

1. Obstructive sleep apnea syndrome. In: American Sleep Disorders Association, eds. The International Classification of Sleep Disorders, Revised: Diagnostic and Coding Manual. Rochester, MN, American Sleep Disorders Association, 1997; pp. 52-58.

2. Young T, Palta M, Dempsey J, Skatrud J, Weber S, Badr $\mathrm{S}$. The occurrence of sleep-disordered breathing among middle-aged adults. $N$ Engl J Med 1993; 328: 1230-1235.

3. Hoffstein V. Is snoring dangerous for your health? Sleep 1996; 19: 506-516.

4. Young T, Finn L, Hla KM, Morgan B, Palta M. Snoring as a part of dose-response relationship between sleep-disordered breathing and blood pressure. Sleep 1996; 19: S202-S205.

5. Seppälä T, Partinen M, Penttilä A, Aspholm R, Tiainen E, Kaukianen A. Sudden death and sleeping history among Finnish men. J Intern Med 1991; 229: 23-28.

6. Stradling JR, Crosby JH, Payne CD. Self reported snoring and daytime sleepiness in men aged 35-64 yrs. Thorax 1991; 46: 807-810.

7. Jennum P, Hein HO, Gyntelberg F. Headache and cognitive dysfunctions in snorers: a cross-sectional study of 3,323 men aged 54 to 74 years: the Copenhagen male study. Arch Neurol 1994; 51: 937-942.

8. Hublin C, Kaprio J, Partinen M, Heikkilä K, Koskenvuo M. Daytime sleepiness in an adult, Finnish population. $J$ Intern Med 1996; 239: 417-423.

9. Guilleminault C, Stoohs R, Clerk A, Simmons J, Labanowski M. From obstructive sleep apnea syndrome to upper airway resistance syndrome: consistency of daytime sleepiness. Sleep 1992; 15: S13-S16.

10. Hoffstein V, Mateika S, Hanly P. Snoring and arousals: a retrospective analysis. Sleep 1995; 18: 866-872.

11. Rywik S, Sznajd J, Williams OD, et al. Poland and US collaborative study on cardiovascular epidemiology: I. Introduction and baseline findings. Am J Epidemiol 1989; 130: 431-445.

12. Johns MW. A new method for measuring daytime sleepiness: the Epworth Sleepiness Scale. Sleep 1991; 14: 540545.

13. WHO MONICA Project Principal Investigators. The World Health Organization MONICA Project (monitoring trends and determinants in cardiovascular disease): a major international collaboration. J Clin Epidemiol 1988; 41: 105-114.

14. Population. Confession. In: Annual Statistics for Poland 1995. Warsaw, GUS 1996; pp. 46-78.
15. Bloom JW, Kaltenborn W, Quan SF. Risk factors in a general population for snoring. Chest 1988; 93: 678-683.

16. Schmidt-Nowara WW, Coultas DB, Wiggins C, Skipper BE, Samet JM. Snoring in a Hispanic-American population: risk factors and association with hypertension and other morbidity. Arch Intern Med 1990; 150: 597-601.

17. Jennum P, SjR1 A. Snoring, sleep apnoea and cardiovascular risk factors: the MONICA II study. Int J Epidemiol 1993; 22: 439-444.

18. Ohayon MM, Guilleminault C, Priest RG, Caulet M. Snoring and breathing pauses during sleep: telephone interview survey of a United Kingdom population sample. $B r$ Med $J$ 1997; 314: 860-863.

19. Gislason T, Benediktsdóttir B, Björnsson JK, Kjartansson G, Kjeld M, Kristbjarnarson H. Snoring, hypertension, and the sleep apnea syndrome: an epidemiologic survey of middle-aged women. Chest 1993; 103: 1147-1151.

20. Martikainen K, Partinen M, Urponen H, Vuori I, Laippala P, Hasan J. Natural evolution of snoring: a 5-year followup study. Acta Neurol Scand 1994; 90: 437-442.

21. Olson LG, King MT, Hensley MJ, Saunders NA. A community study of snoring and sleep-disordered breathing: prevalence. Am J Respir Crit Care Med 1995; 152: 711716.

22. Jennum P, Hein HO, Suadicani P, Gyntelberg F. Cardiovascular risk factors in snorers: a cross-sectional study of 3,323 men aged 54 to 74 years: the Copenhagen male study. Chest 1992; 102: 1371-1376.

23. Hoffstein V. Snoring and nocturnal oxygenation: is there a relationship? Chest 1995; 108: 370-374.

24. Wetter DW, Young TB, Bidwell TR, Badr MS, Palta M. Smoking as a risk factor for sleep-disordered breathing. Arch Intern Med 1994; 154: 2219-2224.

25. Marin M, Gascon JM, Carrizo S, Gispert J. Prevalence of sleep apnoea syndrome in the Spanish adult population. Int J Epidemiol 1997; 26: 381-386.

26. Young T, Finn L, Hla KM, Morgan B, Palta M. Snoring as a part of a dose-response relationship between sleepdisordered breathing and blood pressure. Sleep 1996; 19: S202-S205.

27. Przewozniak K, Zatonski W. Smoking in adult Polish population in the years 1974-1995. In: Zatonski W, Przewozniak K, eds. Smoking in Poland: attitudes, health consequences and prophylaxy. Warsaw, Institute of Oncology 1996; 127-162.

28. Bowen-Davis A. Pharyngitis - acute and chronic. In: Ballantyne J, Groven J, eds. Diseases of the car, nose and throat. London, Butterworths 1971; 75.

29. Fletcher C, Peto R. The natural history of chronic airflow obstruction. Br Med J 1977; 1: 645-648.

30. Olson LG, King MT, Hensley MJ, Saunders NA. A community study of snoring and sleep-disordered breathing: symptoms. Am J Respir Crit Care Med 1995; 15 2: 707710.

31. Gislason T, Almquist M, Eriksson G, Taube A, Boman G. Prevalence of sleep apnea syndrome among swedish men - an epidemiological study. J Clin Epidemiol 1988; 41: 571-576.

32. Bearpark H, Elliott L, Grunstein R, et al. Snoring and sleep apnea. A population study of Australian men. Am J Respir Crit Care Med 1995; 151: 1459-1465. 